\title{
Development of New Visible Spectrophotometric Methods for Quantitative Determination of Almotriptan Malate Using Quinones as Chromogenic Reagents
}

\author{
M. SYAM BAB ${ }^{* a}$, U. VIPLAVA PRASAD ${ }^{\mathrm{a}}$ and B. KALYANA RAMU ${ }^{\mathrm{b}}$ \\ ${ }^{\mathrm{a}}$ Department of Organic Chemistry \& Analysis of Foods Drugs \& Water Laboratories, \\ School of Chemistry, Andhra University, Visakhapatnam-530003, Andhra Pradesh, India \\ ${ }^{\mathrm{b}}$ Department of Chemistry, Maharajah's College (Aided \& Autonomous), \\ Vizianagaram-535002 (AP), India \\ msyambab@gmail.com
}

Received 16 May 2012 / Accepted 4 June 2012

\begin{abstract}
Two simple, sensitive and cost effective visible spectrophotometric methods $\left(\mathrm{M}_{1}-\mathrm{M}_{2}\right)$ were developed for the estimation of almotriptan malate in bulk and dosage forms. The first method $\left(\mathbf{M}_{1}\right)$ is based on the formation of radical anion with the involvement of basic nitrogen in drug (free base form) ( $n$-donor) and chloranilic acid (DHQ) ( $\pi$-acceptor). The purple colored product exhibits absorption maximum at $544 \mathrm{~nm}$ in methanol. The second method $\left(\mathrm{M}_{2}\right)$ is based on the interaction of $N$-alkyl vinyl amine formed from the condensation of the free secondary amine group in the drug and acetaldehyde with $p$-chloranil (TQ) to give vinyl amino substituted quinone. The blue colored product exhibits an absorption maximum at $660 \mathrm{~nm}$ in dioxane. Beer's law obeyed in the concentration range of 25-125 $\mu \mathrm{g} / \mathrm{mL}$ and $20-60 \mu \mathrm{g} / \mathrm{mL}$ for method $\mathrm{M}_{1}$ and $\mathrm{M}_{2}$ respectively. Commercially available tablets were analyzed; the results obtained by the proposed methods were in good agreement with the labeled amounts. These methods offer the advantages of rapidity, simplicity, sensitivity and normal cost and can be easily applied to resource-poor settings without the need for expensive instrumentation and reagents.
\end{abstract}

Keywords: Anti migraine, Quinones, Acetaldehyde, Assay, Chloranilic acid, Spectrophotometer, Validation

\section{Introduction}

Almotriptan malate (AM) (Figure 1) is a selective and potent serotonin 5-hydroxy trytamine1B/1D (5-HT 1B/1D) receptor agonist. It is chemically designated as 1[[[3-[2-(Di methyl amine) ethyl]-1H-indol-5-yl] methyl] sulfonyl] pyrrolidine \pm - hydroxy butanedioate ${ }^{1}$ (1:1). Its empirical formula is $\mathrm{C}_{17} \mathrm{H}_{25} \mathrm{~N}_{3} \mathrm{O}_{2} \mathrm{~S}_{2} \mathrm{C}_{4} \mathrm{H}_{6} \mathrm{O}_{5}$ representing molecular weight of 469.56. It is a white to slightly yellow crystalline powder that is soluble in water and sparingly 
soluble in methanol. Almotriptan is available in market as conventional tablets (AXERT). The drug is absorbed well orally, with an absolute bioavailability of around $70 \%$. The drug is used to treat severe migraine headaches and vascular headaches; acute treatment of migraine attacks with or without aura. The drug binds with high affinity to 5-HT 1D, 5-HT $1 \mathrm{~B}$ and $5-\mathrm{HT} 1 \mathrm{~F}$ receptors. Because of the particular distribution of the 5-HT 1B/1D receptors, almotriptan basically constricts the human meningeal arteries; therefore it has a limited effect on arteries supplying blood to the brain and little effect on cardiac and pulmonary vessels. Ameliorate migraine through selective constriction of certain intracranial blood vessels, inhibition of neuro peptide release and reduced transmission in trigeminal pain pathway.<smiles>CN(C)CCc1c[nH]c2ccc(CS(=O)(=O)N3CCCC3)cc12</smiles>

Figure 1. Chemical structure of almotriptan malate

In literature, several analytical methods such as HPLC ${ }^{2-3}$, HPTLC $^{4}$, LC-ESI-MS/MS ${ }^{5}$, UV spectrometric ${ }^{6,7}$ and fluorometric and colorimetric ${ }^{8}$ have been reported for the determination of AM in biological fluids (considerable more) and formulations (less).

The main purpose of the present study was to establish a relatively simple, sensitive, validated and inexpensive visible spectrophotometric methods for the determination of AM in pure form and in pharmaceutical dosage forms, since most of the previous methods involve sophisticated equipments which are costly and pose problems of maintenance.

A direct chemical analysis based on the reactivity of the intact molecule without cleavage is not frequently encountered. The methods that are based on the charge-transfer complexation are usually rapid and simple to perform $\pi$ - acceptors (quinones such as $2,3,5$, 6,-tetrachloro-p-benzoquinone) (TQ), DHQ (2,5-dihydroxy 3,6-dichloro-1,4-benzoquinone, chloranilic acid) are known to yield charge-transfer complexes with a variety of electron donors. The present work describes an improved direct simple two analytical procedures that can be applied to quality control laboratories for the analysis of pharmaceutical products containing AM.

The proposed methods for AM determination have many advantages over other analytical methods due to its rapidity, normal cost and environmental safety. Unlike HPLC, HPTLC procedures, the instrument is simple and is not costly. Economically, all the analytical reagents are inexpensive and available in any analytical laboratory. These methods can be extended for the routine quality control analysis of pharmaceutical products containing AM.

\section{Experimental}

A Milton roy UV/Visible spectrophotometer model-1201 with $10 \mathrm{~mm}$ matched quartz cells was used for all spectral measurements. All the chemicals used were of analytical grade. AXERT tablets procured from Ortho Mc Nell Pharmaceuticals, USA.

Chloranilic acid solution(DHQ, Sd-Fine, $0.1 \%, 4.785 \times 10-3 \mathrm{M}$ prepared by dissoloving $100 \mathrm{mg}$ of chloranilic acid in $20 \mathrm{~mL}$ isopropanol initially followed by dilution with methanol to $100 \mathrm{~mL}$ ), Chloranil (TQ, BDH, $0.1 \%, 4.067 \times 10^{-3} \mathrm{M}$ prepared by dissolving $100 \mathrm{mg}$ of chloranil in $100 \mathrm{~mL}$ of 1,4-dioxane) were prepared and acetaldehyde used directly. 


\section{Preparation of standard and sample drug stock solution}

One $\mathrm{mg} \mathrm{mL}^{-1}$ stock solution of AM (in free base form) was prepared by dissolving an accurately weighted quantity of $\mathrm{AM}$ (pure or tablet powder) equivalent to $100 \mathrm{mg}$ of it in chloroform and treated with $5 \mathrm{~mL}$ of $10 \% \mathrm{Na}_{2} \mathrm{CO}_{3}$ solution, followed by extraction with chloroform $(3 \times 15 \mathrm{~mL})$ and dilution to $100 \mathrm{~mL}$ with the same solvent. The chloroform extract $(50 \mathrm{~mL})$ was evaporated to dryness and the residue was dissolved in $100 \mathrm{~mL}$ of methanol to get $500 \mu \mathrm{g} / \mathrm{mL}$ for method $\mathrm{M}_{1}$ and the other chloroform extract $(50 \mathrm{~mL}$ ) was evaporated to dryness and the residue was dissolved initially in $5 \mathrm{~mL} \mathrm{DMF}$ and the volume was brought to $50 \mathrm{~mL}$ with1, 4-dioxane for method $\mathrm{M}_{2}$. The working standard solution of AM $\left(200 \mu \mathrm{g} / \mathrm{mL}\right.$ for method $\left.\mathrm{M}_{2}\right)$ was obtained by appropriately diluting the standard stock solution by using the same solvent.

\section{Recommended procedure/Assay}

\section{Method $M_{1}$}

Aliquots of standard free base AM drug solution $(0.5-2.5 \mathrm{~mL}, 500 \mu \mathrm{g} / \mathrm{mL})$ in chloroform were delivered into $10 \mathrm{~mL}$ graduated tubes. $2.0 \mathrm{~mL}$ of $\left(4.785 \times 10^{-3} \mathrm{M}\right) \mathrm{CA}$ in methanol was added and kept aside for 5 minutes. Then the volumes of the contents were made up to the mark with methanol. The absorbance was measured (Figure 2) against a reagent blank at 544 $\mathrm{nm}$ within the stability period (30 min.). The amount of the drug was computed from the appropriate calibration graph (Figure 4).

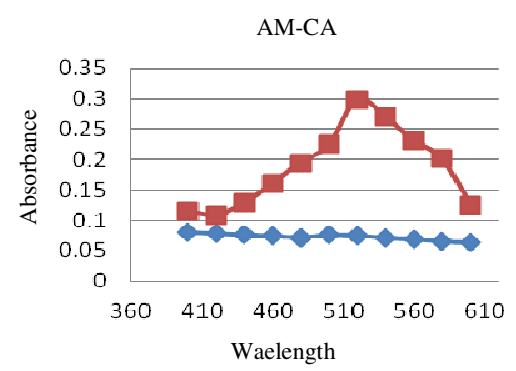

Figure 2. Absorption spectra of AM-CA

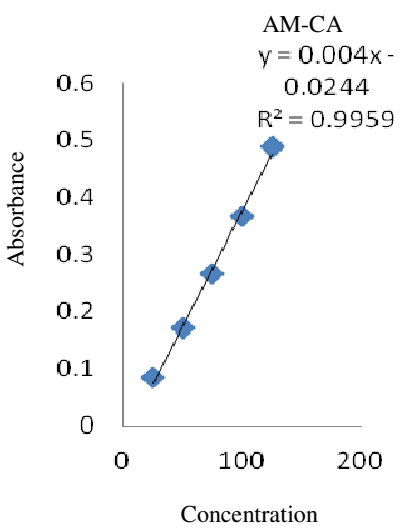

Figure 4. Beer's Law plot of AM-CA $\left(\mathrm{M}_{1}\right)$

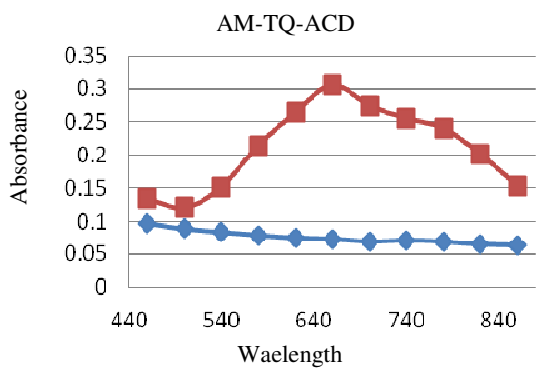

Figure 3. Absorption spectra of AM-TQ-ACD

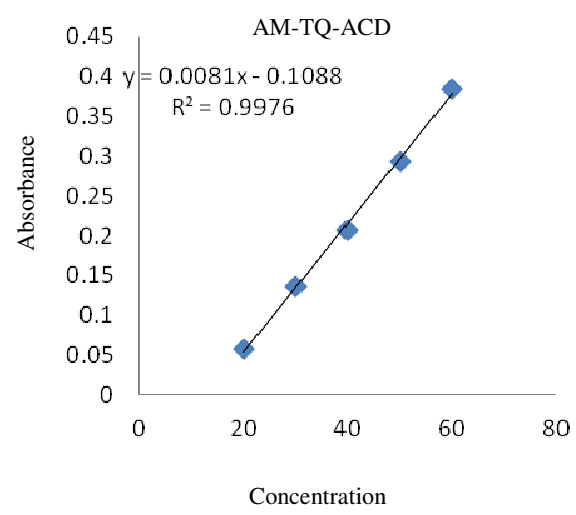

Figure 5. Beer's Law plot of AM-TQ-ACD $\left(\mathrm{M}_{2}\right)$ 


\section{Method $\mathrm{M}_{2}$}

Aliquots of working standard AM drug solution $(200 \mu \mathrm{g} / \mathrm{mL})$ such as $1.0,1.5,2.0,2.5 \mathrm{~mL}$ and $3.0 \mathrm{~mL}$ were taken separately in a series of $10 \mathrm{~mL}$ calibrated tubes. Then $0.5 \mathrm{~mL}$ of acetaldehyde and $1 \mathrm{~mL}$ TQ $\left(4.067 \times 10^{-3} \mathrm{M}\right)$ were added successively and shaken for 2 minutes and kept aside for 15 minutes at room temperature and made up to the mark with 1, 4-dioxane and sonicated for $1 \mathrm{~min}$. The violet colored species was obtained and it was stable for $1 \mathrm{~h}$. The absorbance of the colored species was measured at $660 \mathrm{~nm}$ against the reagent blank (Figure 3 ). The calibration graph (Figure 5) was constructed by plotting the drug concentration versus absorbance.

\section{Results and Discussion}

In developing these methods, systematic study of the effects of various parameters were undertaken by varying one parameter at a time and controlling all others fixed. The effect of various parameters such as time, volume and strength of CA, TQ, acetaldehyde, stability of colored species and solvent for final dilution of the colored species were studied and the optimum conditions were established. The solvent for final dilution tried with different solvents such as acetinitrile, tetrahydrofuran, ethylene glycol, dimethyl ether, methanol, 1, 4-dioxane. Among these, methanol and 1, 4-dioxane was found to be superior for final dilution for methods $\mathrm{M}_{1} \& \mathrm{M}_{2}$ respectively. It enhances not only the absorbance but also insert reproducible values for colored species. The optical characteristics such as Beer's law limit, Sandell's sensitivity, molar absorptivity, percent relative standard deviation, (calculated from the six measurements containing $3 / 4^{\text {th }}$ of the amount of the upper Beer's law limits) were calculated and the results are summarized in Table 1. Regression characteristics like standard deviation of slope $\left(S_{b}\right)$, standard deviation of intercept $\left(\mathrm{S}_{\mathrm{a}}\right)$, standard error of estimation $\left(\mathrm{S}_{\mathrm{e}}\right)$ and \% range of error $(0.05$ and 0.01 confidence limits) were calculated and are shown in Table 1.

Table 1. Optical characteristics, precision and accuracy of the proposed methods

\begin{tabular}{lcc}
\hline \multicolumn{1}{c}{ Parameters } & Method $\mathrm{M}_{1}$ & Method $\mathrm{M}_{2}$ \\
\hline$\lambda_{\max }, \mathrm{nm}$ & 544 & 660 \\
Beer's law limit, $\mu \mathrm{g} / \mathrm{mL}$ & $25-125$ & $20-60$ \\
Sandell's sensitivity, & 0.028079371 & 0.019323671 \\
$\mu \mathrm{g} / \mathrm{cm}^{2} / 0.001$ abs. unit & & \\
Molar absorptivity & 16722.5968 & 24299.73 \\
(Litre/mole/cm) & & \\
Regression equation & & \\
$*$ Y= a +b x & -0.024 & -0.108 \\
Intercept (a) & 0.004 & 0.008 \\
Slope(b) & 1.03 & 1.56 \\
\%RSD & & \\
$\%$ Range of errors(95\% & & \\
Confidence limits) & 1.08 & 1.64 \\
0.05 significance level & 1.695 & 2.57 \\
0.01 significance level & & \\
\hline
\end{tabular}

$* Y=a+b x$, where $Y$ is the absorbance and $x$ is the concentration of $A M$ in $\mu \mathrm{g} / \mathrm{mL}$

Commercial formulations containing AM were successfully analyzed by the proposed methods. The values obtained by the proposed and reference methods for formulations were compared statistically by the $t$-and $F$-test and found not to differ significantly. As an additional 
demonstration of accuracy, recovery experiments were performed by adding a fixed amount of the drug to the pre analyzed formulations at three different concentration levels. These results are summarized in Table 2 . The ingredients usually present in formulations of AM did not interfere with the proposed analytical methods.

Table 2. Analysis of AM in pharmaceutical formulations

\begin{tabular}{|c|c|c|c|c|c|c|c|}
\hline \multirow{2}{*}{ 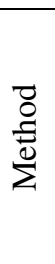 } & \multirow{2}{*}{ 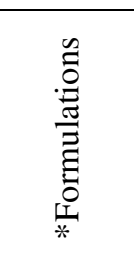 } & \multirow{2}{*}{ 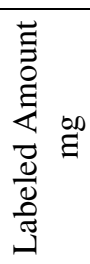 } & \multicolumn{3}{|c|}{ Found by Proposed Methods } & \multirow{2}{*}{ 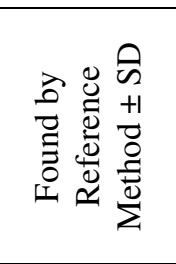 } & \multirow{2}{*}{ 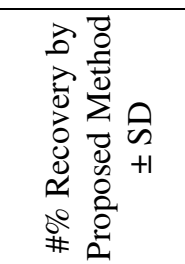 } \\
\hline & & & $\begin{array}{l}* * \text { Amount } \\
\text { found } \pm \text { SD }\end{array}$ & $\mathrm{t}$ & $\mathrm{F}$ & & \\
\hline \multirow{2}{*}{$\mathrm{M}_{1}$} & Tablet-1 & 6.25 & $6.23 \pm 0.024$ & 1.5 & 1.92 & $6.21 \pm 0.034$ & $99.62 \pm 0.39$ \\
\hline & Tablet-2 & 12.5 & $12.43 \pm 0.78$ & 0.15 & 3.71 & $12.44 \pm 0.15$ & $99.41 \pm 0.63$ \\
\hline \multirow{2}{*}{$\mathrm{M}_{2}$} & Tablet-1 & 6.25 & $6.19 \pm 0.046$ & 2.66 & 1.83 & $6.21 \pm 0.034$ & $99.02 \pm 0.73$ \\
\hline & Tablet-2 & 12.5 & $12.35 \pm 0.079$ & 1.41 & 3.66 & $12.44 \pm 0.15$ & $98.77 \pm 0.63$ \\
\hline
\end{tabular}

*Tablet 1 and Tablet 2: AXERT tablets of Ortho Mc Nell Pharmaceuticals, USA, **Average \pm Standard deviation of six determinations, the $t$ - and F-values refer to comparison of the proposed method with UV reference method. Theoretical values at $95 \%$ confidence limits $t=2.57$ and $F=5.05$. \# Recovery of $10 \mathrm{mg}$ added to the pre analyzed sample (average of three determinations). Reference method (reported UV method) using methanol $\left(\lambda_{\max }=227 \mathrm{~nm}\right.$ )

\section{Chemistry of colored species:}

\section{Method $M_{1}$}

The interactions of any of the investigated compounds with poly halo and poly cyano quinone $\pi$-acceptors in non polar solvents was found to produce colored charge-transfer complexes with low molecular absorptivity values. In polar solvents such as acetonitrile or methanol or 1, 4-dioxane, complete electron transfer from donor to the acceptor moiety takes place with formations of intensity colored radical ions with higher molar absorptivity values according to the following scheme.

$$
\mathrm{D}:+\mathrm{A} \rightleftharpoons(\mathrm{D}-\mathrm{A}) \stackrel{\text { Polar solvent }}{=} \mathrm{A}^{-}+\mathrm{D}^{+}
$$

The position of equilibrium depends on the donor, the acceptor and the solvent. The dissociation of the D-A complex is promoted by donors of low ionization potential, acceptors of high electron affinity and solvents with strong solvating powers. Tertiary nitrogen of AM permits for the development of colored radical ion in the present investigation.

\section{Method $\mathrm{M}_{2}$}

Henbest and his co-workers ${ }^{9,10}$ found that many secondary or primary amines react with TQ and acetaldehyde. The $N$-alkyl vinyl amine obtained by condensing the amine with acetaldehyde reacts with TQ to give vinyl amino substituted quinone to give blue color. The proposed method exploits structural features aromatic secondary amine of the AM molecule due to the presence of cyclic imino group in indole portion. The nature of colored species formation with TQ-acetaldehyde reagent is initial $N$-alkyl vinyl amine formation with acetaldehyde then followed by formation of colored $N$-alkyl vinyl amino substituted quinones with $\mathrm{T} \mathrm{Q}$ has been assumed in the scheme (Figure 6). 


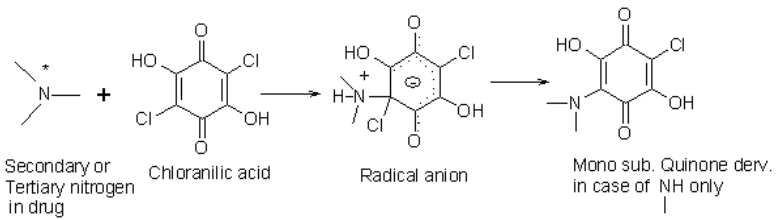

*sec. or ter. Nitrogen of drug involve in ion radical formation with quinone derivatives

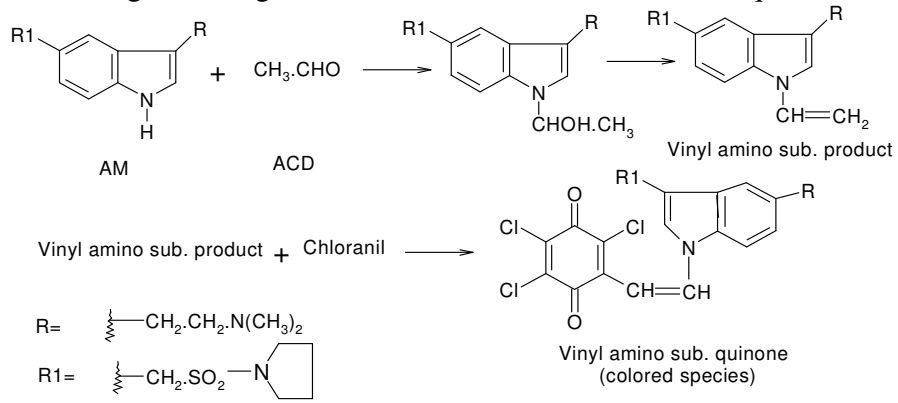

Figure 6. Scheme of the reactions for method $\mathrm{M}_{1} \& \mathrm{M}_{2}$

\section{Conclusion}

The reagents utilized in the proposed method are normal cost, readily available and the procedure does not involve any critical reaction conditions or tedious sample preparation. The proposed visible spectrophotometric methods possesses reasonable precision, accuracy and are simple, sensitive and can be used as alternative methods to the reported ones for the routine determination of AM depending on the need and situation.

\section{Acknowledgement}

The authors (M.S Bab \&B.K. Ramu) are grateful to University Grants Commission, New Delhi, for providing financial assistance under the award of Teacher Fellowship (XI plan).

\section{References}

1. Maryadele JON. The Merck Index $14^{\text {th }}$ Ed., Merck \&Co Inc., New Jersey, 2006.

2. Suneetha A and Syama Sundar B, J Chin Chem Soc., 2010, 57(5A), 1067-1070.

3. Kumar AP, Ganesh V, Subba Rao D, Anil C, Venugopal Rao B, Hari Krishna V S, Suneetha A and Syama Sundar B, J Pharm Biomed Anal., 2008, 46(4), 792-798.

4. Suneetha A and Syamsundar B, Indian J Pharma Sci., 2010, 72(5), 629-32.

5. Nageshwar rao R, Guruprasad K, Gangu naidu Ch, Raju B, Srinivas R, J Chromatogr B Anal Technol Biomed Life Sci., 2012, 891-892, 44-51.

6. Suneetha A and Syama Sundar B, Asian J Res Chem., 2010, 3(1), 142-144.

7. Suneetha A, Kathirvel S, Prathyusha A and Anusha K, www.scientificipca.Org/paper/ 2011/09/13/201109131246120A.docx.

8. EI-Bagary Ramzia, Mohammed N G and Nasr H A, J Chem Pharm Res., 2011, 3(4), 304-314.

9. Fekria M. Abou Attia, II Farmaco, 2000, 55(11-12), 659-664.

10. Henbest H B, Buckley O and Dunstan, J Chem Soc., 1957, 4, 880. 